\title{
Mối quan hệ giữa quy mô và năng suất đất của nông hộ trồng lúa Đồng bằng Sông Cửu Long
}

\section{The relationship between farm size and land productivity of rice farming households in the Mekong Delta}

\author{
Nguyễn Lan Duyên ${ }^{1 *}$, Nguyễn Tri Khiêm² \\ ${ }^{1}$ Trường Đại học An Giang, Việt Nam \\ ${ }^{2}$ Trường Đại học Cần Thơ, Việt Nam \\ *Tác giả liên hệ, Email: nlduyen@agu.edu.vn
}

\section{THÔNG TIN}

DOI: $10.46223 / \mathrm{HCMCOUJS}$. econ.vi.13.3.1510.2018

Ngày nhận: 20/11/2017

Ngày nhận lại: 28/03/2018

Duyệt đăng: 10/07/2018

Tù khóa:

canh tác lúa, năng suất đất, quy mô đất canh tác

\section{TÓM TÁT}


households' working-age members, and their residence. The study also reveals the factor negatively affecting land

Keywords:

farm size, land productivity, rice cultivation productivity which is the distance from the household to the rice field. The paper then proposes some solutions for farmers to make effective use of resources and reasonable scale investment in rice cultivation to maximize land productivity.

\section{Giới thiệu}

Gạo là lương thực chủ lực cho 3 tỷ người trên toàn thế giới; trong số 1,1 tỷ người nghèo trên thế giới có thu nhập ít hơn một đô la mỗi ngày có gần 700 triệu người sống ở các nước trồng lúa ở châu Á (Tan, Heerink, Kuyvenhoven, \& Qu, 2010) bao gồm cả Việt Nam. Đồng bằng sông Cửu Long (ĐBSCL) là vựa lúa lớn nhất của Việt Nam, với diện tích trồng lúa năm 2014 gần 4,3 triệu hecta; cung ứng 25,2 triệu tấn lúa cho nền kinh tế và chiếm hơn $56 \%$ tổng sản lượng lúa cả nước (Cục Trồng trọt thuộc Bộ nông nghiệp và phát triển nông thôn, 2014) và sản xuất lúa là một ngành sản xuất hàng hóa quan trọng của vùng (T. L. Pham, Huynh, \& Tran, 2011). Tuy nhiên, trước áp lực cạnh tranh cũng như nhu cầu về sản lượng đã tăng vụ sản xuất lúa từ 2 lên 3 vụ (hình thức đê bao khép kín) cùng với chính sách điều chỉnh luật đất đai đã phần nào có những tác động tích cực lẫn tiêu cực đến hiệu quả sản xuất lúa.

Mặc dù bị ảnh hưởng lớn bởi sự biến đổi khí hậu cũng như tác động từ các đập thủy điện ở đầu nguồn Sông MeKong nhưng đến nay nhiều địa phương vẫn còn canh tác theo hình thức 3 vụ lúa/năm. Để đo lường mối quan hệ giữa quy mô đất và năng suất thường sử dụng những thước đo năng suất khác nhau. Một số nghiên cứu liên quan đã sử dụng năng suất hoặc giá trị sản lượng trên một đơn vị diện tích - gọi chung là năng suất đất - để phân tích mối quan hệ giữa quy mô đất và năng suất. Trong khi năng suất đất là một biện pháp quan trọng có thể được sử dụng để đánh giá sự khác biệt về hiệu quả của nông hộ (Nkonde, Jayne, Richardson, \& Place, 2015). Đồng thời những học giả này cũng đã đưa ra cách đo lường năng suất khác so với nhiều nghiên cứu trong và ngoài nước sử dụng, theo họ chỉ tiêu năng suất đất được xác định bằng giá trị thuần của tổng sản lượng cây trồng trên quy mô. Với cách đo lường này, bài báo sẽ mang đến một kết quả hoàn toàn mới so với những nghiên cứu trước đây và giúp nông hộ xác định ngưỡng quy mô hợp lý nhằm tối đa hóa năng suất đất cho nông hộ trồng lúa ĐBSCL.

\section{Phương pháp luận và phương pháp nghiên cứu}

\subsection{Phương pháp luận}

Năng suất đất hay giá trị thuần của sản lượng cây trồng/quy mô (Y) (Nkonde et al. 2015), được xác định bằng cách:

$$
\mathrm{Y}=\left\{\mathrm{GV}_{\mathrm{i}}-\sum \mathrm{VC}_{\mathrm{i}}-\sum \mathrm{FC}_{\mathrm{i}}\right\} / \sum \mathrm{A}_{\mathrm{i}}
$$

Trong đó, GV là tổng giá trị sản lượng lúa của nông hộ, VC là tổng chi phí biến đổi, FC là tổng chi phí cố định và $\mathrm{A}$ là quy mô đất sản xuất lúa, $\mathrm{i}$ thể hiện vụ mùa sản xuất thứ $\mathrm{i}$. Chi phí biến đổi (bao gồm chi phí cơ hội của lao động gia đình, chi phí thuê lao động, giống, phân, thuốc và chi phí thuê máy móc - vật nuôi phục vụ làm đất), trong đó chi phí cơ hội của lao động gia đình được tính bằng cách nhân tiền lương với số ngày lao động gia đình làm việc trên ruộng 
lúa của những thành viên trong độ tuổi lao động từ 16 - 59 tuổi dựa trên mức lương của chính họ ở địa phương. Chi phí thuê lao động được tính bằng số ngày thuê nhân với tiền thuê lao động hiện tại ở địa phương. Riêng chi phí cố định được tính dựa trên những tài sản (máy cày, máy xới, ...) sử dụng trong mùa vụ sản xuất nông nghiệp thông qua giá thuê tài sản tại địa phương, nhưng công cụ tưới tiêu (máy bơm) thì không được tính dựa vào giá thuê trên thị trường mà được tính bằng công thức $(\mathrm{FC}=\mathrm{c} / \mathrm{n}+(\mathrm{c} * \mathrm{r}))$, trong đó $\mathrm{FC}$ là chi phí cố định của tài sản, $\mathrm{c}$ là giá hoặc chi phí của tài sản lúc mới mua, $n$ là số năm hoạt động của tài sản, $r$ là tỷ lệ khấu hao đều hàng năm). Với giả định hiệu suất không đổi theo quy mô (Constant return to scale).

Các nghiên cứu đã sử dụng phương pháp ước lượng bình phương bé nhất (OLS) để ước lượng mối quan hệ giữa quy mô và năng suất đất qua phương trình (2):

$$
\mathrm{NSDAT}=\mathrm{C}+\beta \ln Q \mathrm{UYMO}+\varepsilon
$$

Nếu $\beta<0$ và có ý nghĩa thống kê thì tồn tại mối quan hệ ngược (Carter, 1984; Heltberg, 1998) giữa quy mô với năng suất đất.

Tuy nhiên, công thức (2) thường bị chỉ trích do bỏ sót những yếu tố khác có ảnh hưởng đến năng suất đất như khác biệt trong chất lượng đất (Lamb, 2003), sự khác nhau giữa các hộ (Assuncao \& Ghatak, 2003), sự manh mún đất (Wu, Liu, \& Davis, 2005) cùng với những yếu tố khác. Do đó, Li, Feng, You, và Fan (2013) đã cải tiến công thức (2) bằng việc bổ sung các biến ngoại sinh (bao gồm nguồn lực của hộ thể hiện nguồn nhân lực và vốn xã hội như giáo dục, tập huấn kỹ thuật, kinh nghiệm cá nhân, mạng lưới xã hội và nguồn lực sẵn có), đồng thời Nkonde và cộng sự (2015) cũng bổ sung thêm những biến về khả năng quản lý cây trồng nhằm kiểm soát ảnh hưởng của những yếu tố trên đến năng suất đất của nông hộ trồng lúa. Để xác định mối quan hệ giữa quy mô và năng suất đất bằng phương pháp OLS thông qua phương trình (3).

$$
\mathrm{NSDAT}=\beta_{1}+\beta_{2} \mathrm{QUYMO}+\beta_{3} \mathrm{QUYMO}{ }^{2}+\mathrm{Z} \beta_{4}+\mathrm{X} \beta_{5}+\varepsilon
$$

Trong đó, $Z$ là vectơ các biến ngoại sinh (đặc điểm chủ hộ, điều kiện thổ nhưỡng và hiệu quả cố định của huyện), $X$ là vectơ các yếu tố về quản lý cây trồng có ảnh hưởng đến năng suất, $\beta_{\mathrm{i}}$ là các hệ số ước lượng và $\varepsilon$ là sai số ngẫu nhiên.

Trên cơ sở các luận điểm vừa trình bày, bài viết xây dựng mô hình (3) nghiên cứu mối quan hệ giữa quy mô và năng suất đất được thể hiện như trong Bảng 1.

Trong mô hình (3), biến phụ thuộc NSDAT là giá trị thuần của sản lượng lúa/quy mô của nông hộ (triệu đồng/ha). Ý nghĩa của các biến và kỳ vọng về dấu đối với các hệ số $\beta i$ trong mô hình (3) được trình bày trong Bảng 1 .

\section{Bảng 1}

Kỳ vọng về dấu của các hệ số $\beta_{\mathrm{i}}$ trong mô hình (3)

\begin{tabular}{cccc}
\hline Tên biến & \multicolumn{1}{c}{$\begin{array}{c}\text { Diễn giải và } \\
\text { đơn vị đo lường }\end{array}$} & Nghiên cứu có liên quan & $\begin{array}{c}\text { Kỳ vọng } \\
\text { về dấu các } \\
\boldsymbol{\beta}_{\mathbf{i}}\end{array}$ \\
\hline QUYMO & $\begin{array}{l}\text { Diện tích fất trồng lúa của } \\
\text { nông hộ (ha) }\end{array}$ & $\begin{array}{l}\text { Mahmood và Nadeem-uh-haque (1981), } \\
\text { Byiringiro và Readon (1996), Heltberg }\end{array}$ & + \\
\hline
\end{tabular}




\begin{tabular}{|c|c|c|c|}
\hline Tên biến & $\begin{array}{l}\text { Diễn giải và } \\
\text { đơn vị đo lường }\end{array}$ & Nghiên cứu có liên quan & $\begin{array}{c}\text { Kỳ vọng } \\
\text { về dấu các } \\
\beta_{\mathbf{i}}\end{array}$ \\
\hline & & $\begin{array}{l}\text { (1998), Dorward (1999), H. V. Pham, } \\
\text { MacAulay, và Marsh (2007), Barrett, } \\
\text { Bellemare, và Hou (2010), Ali và } \\
\text { Deininger (2015), Nkonde và cộng sự } \\
\text { (2015) }\end{array}$ & \\
\hline QUYMO $^{2}$ & $\begin{array}{l}\text { Bình phương diện tích đất } \\
\text { trồng lúa của nông hộ }\end{array}$ & $\begin{array}{l}\text { Mahmood và Nadeem-uh-haque (1981), } \\
\text { Byiringiro và Readon (1996), Heltberg } \\
\text { (1998), Dorward (1999), H. V. Pham và } \\
\text { cộng sự (2007), Ali và Deininger } \\
\text { (2015), Nkonde và cộng sự (2015) }\end{array}$ & - \\
\hline QUYMOHO & $\begin{array}{l}\text { Số thành viên trong tuổi lao } \\
\text { động của hộ tham gia trồng } \\
\text { lúa (số lao động) }\end{array}$ & $\begin{array}{l}\text { Heltberg (1998), Barrett và cộng sự } \\
\text { (2010), Gaurav và Mishra (2015) }\end{array}$ & + \\
\hline TGDINHCU & $\begin{array}{l}\text { Số năm sinh sống ở địa } \\
\text { phương (năm) }\end{array}$ & Nkonde và cộng sự (2015) & + \\
\hline TNKHAC & $\begin{array}{l}\text { Thu nhập ngoài nông } \\
\text { nghiệp }\end{array}$ & Xu và Jeffrey (1998) & + \\
\hline TINDUNG & $\begin{array}{l}\text { Lượng tiền vay được từ tổ } \\
\text { chức chính thức, bán chính } \\
\text { thức và phi chính thức } \\
\text { (triệu đồng/hộ/năm) }\end{array}$ & Gaurav và Mishra (2015) & + \\
\hline TRAVINH & $\begin{array}{l}\text { Có trị số là } 1 \text { nếu nông hộ } \\
\text { sống ở Trà Vinh và là } 0 \text { nếu } \\
\text { sống ở những tỉnh khác }\end{array}$ & Byiringiro và Reardon (1996) & + \\
\hline THAMNIEN & $\begin{array}{l}\text { Số năm thâm niên trồng lúa } \\
\text { của chủ hộ (năm) }\end{array}$ & $\begin{array}{l}\text { Byiringiro và Readon (1996), Li và } \\
\text { cộng sự (2013) }\end{array}$ & + \\
\hline RUIRO & $\begin{array}{l}\text { Có trị số là } 1 \text { nếu gặp rủi ro } \\
\text { trong canh tác lúa và có giá } \\
\text { trị } 0 \text { là ngược lại }\end{array}$ & Heltberg (1998) & - \\
\hline KCRUONG & $\begin{array}{l}\text { Khoảng cách từ nơi sinh } \\
\text { sống của nông hộ đến thửa } \\
\text { ruộng trồng lúa lớn nhất } \\
(\mathrm{km})\end{array}$ & $\begin{array}{l}\text { Byiringiro và Readon (1996), Yamano } \\
\text { và Kijima (2010), Ali và Deininger } \\
\text { (2015) }\end{array}$ & - \\
\hline PHUSA & $\begin{array}{l}\text { Có trị số là } 1 \text { nếu đất phù } \\
\text { sa, có giá trị } 0 \text { nếu ngược } \\
\text { lại. }\end{array}$ & $\begin{array}{l}\text { Bhalla và Roy (1988), Ali và Deininger } \\
\text { (2015), Nkonde và cộng sự (2015) }\end{array}$ & + \\
\hline TAPHUAN & $\begin{array}{l}\text { Có trị số là } 1 \text { nếu chủ hộ có } \\
\text { tham gia các lớp tập huấn } \\
\text { và có giá trị } 0 \text { là ngược lại }\end{array}$ & $\begin{array}{l}\text { Li và cộng sự (2013), Gaurav và Mishra } \\
\text { (2015) }\end{array}$ & + \\
\hline
\end{tabular}

Nguồn: Tác giả tổng hợp từ các nghiên cứu có liên quan 


\subsection{Phương pháp nghiên cúu}

Số liệu thứ cấp về nông hộ được thu thập từ Ủy ban nhân dân, Sở nông nghiệp và phát triển nông thôn các tỉnh, Niên giám Thống kê Việt Nam, các nghiên cứu được công bố trên các tạp chí trong và ngoài nước. Các thông tin này dùng mô tả về nông hộ nhằm nêu bật tính tất yếu của nông nghiệp, nông thôn và nông dân trên địa bàn nghiên cứu.

Số liệu sơ cấp được thu thập từ điều tra trực tiếp những nông hộ trồng lúa ở 3 tỉnh vùng ĐBSCL là Hậu Giang, Trà Vinh và Kiên Giang. Đây là những tỉnh có mô hình canh tác thuần lúa (Theo số liệu thống kê 2014 thì Kiên Giang có quy mô lớn nhất chiếm 17,7\%, Trà Vinh chiếm 5,6\% và Hậu Giang chiếm 4,8\% so với tổng quy mô vùng ĐBSCL (Tổng cục Thống kê, 2016)). Các nông hộ được chọn một cách ngẫu nhiên và tiến hành phỏng vấn trực tiếp chủ hộ hoặc người trực tiếp sản xuất trong mỗi nông hộ thông qua bảng hỏi soạn sẵn. Những thông tin được thu thập gồm: đặc điểm nhân khẩu của nông hộ, tình hình sử dụng đất, đặc điểm sản xuất lúa (các khoản chi phí và thu nhập) cho vụ đông xuân, hè thu và thu đông năm 2016, những rủi ro gặp phải trong sản xuất lúa và cách thức quản lý trong quá trình canh tác lúa của mỗi nông hộ. Cuộc điều tra được thực hiện vào những tháng đầu năm 2017. Mẫu khảo sát bao gồm 337 nông hộ được phân phối ở các địa phương thuộc ĐBSCL như sau: 115 hộ ở Hậu Giang (chiếm 34,13\% số hộ được khảo sát), 100 hộ ở Kiên Giang (chiếm 29,67\%) và 122 hộ ở Trà Vinh (chiếm 36,20\%).

Mô hình hồi qui tuyến tính (3) được ước lượng bằng phương pháp bình phương bé nhất để tìm mối quan hệ giữa quy mô và năng suất đất của các nông hộ trồng lúa ở ĐBSCL. Dựa trên kết quả ước lượng đó, nghiên cứu sẽ sử dụng phương pháp thống kê để xác định ngưỡng quy mô tối ưu nhằm tối đa hóa năng suất đất cho nông hộ.

\section{Kết quả và thảo luận}

\subsection{Tổng quan về nông hộ}

Đặc điểm nhân khẩu học của hộ trồng lúa được tóm tắt trong Bảng 2. Số thành viên trung bình của hộ là 4 người, và số thành viên trong độ tuổi lao động trung bình là 3 người/hộ, đây là lực lượng lao động dự trữ sẵn sàng phục vụ cho hoạt động sản xuất lúa của gia đình đồng thời giảm gánh nặng thuê mướn lao động với giá cao khi vào vụ.

\section{Bảng 2}

Các chỉ tiêu cơ bản của nông hộ trồng lúa ĐBSCL năm 2016

\begin{tabular}{lccccc}
\hline \multicolumn{1}{c}{ Tiêu chí } & Đơn vị tính & $\begin{array}{c}\text { Trung } \\
\text { bình }\end{array}$ & $\begin{array}{c}\text { Lớn } \\
\text { nhất }\end{array}$ & $\begin{array}{c}\text { Nhỏ } \\
\text { nhất }\end{array}$ & Độ lệch \\
\hline Số thành viên của hộ & Người/hộ & 4,45 & 10,00 & 1,00 & 1,28 \\
Số thành viên trên 16 tuổi & Người/hộ & 2,76 & 6,00 & 0,00 & 1,03 \\
Thời gian sống ở địa phương & Năm & 47,72 & 81,00 & 10,00 & 12,43 \\
Số năm kinh nghiệm & Năm & 32,32 & 65,00 & 3,00 & 13,16 \\
Trình độ học vấn & Năm đi học & 6,71 & 15,00 & 0,00 & 2,97 \\
\hline
\end{tabular}




\begin{tabular}{lccccc}
\hline \multicolumn{1}{c}{ Tiêu chí } & Đơn vị tính & $\begin{array}{c}\text { Trung } \\
\text { bình }\end{array}$ & $\begin{array}{c}\text { Lớn } \\
\text { nhất }\end{array}$ & $\begin{array}{c}\text { Nhỏ } \\
\text { nhất }\end{array}$ & Độ lệch \\
\hline $\begin{array}{l}\text { Khoảng cách từ nhà tới } \\
\text { ruộng lúa }\end{array}$ & Km & 3,95 & 13,00 & 0,00 & 2,15 \\
\hline
\end{tabular}

Nguồn: Kết quả được tổng hợp từ số liệu tự khảo sát năm 2017

Thời gian sống trung bình tại địa phương của hộ là 48 năm và có thâm niên canh tác lúa trung bình là 32 năm, đây là khoảng thời gian khá dài để họ tích luỹ kinh nghiệm trong quá trình canh tác lúa góp phần gia tăng hiệu quả sản xuất cho nông hộ. Trình độ học vấn của nông hộ còn tương đối thấp trung bình là 7 năm với độ lệch chuẩn là 3 năm, đây chính là trở ngại khá lớn cho nông dân trong việc tiếp thu kiến thức và áp dụng khoa học công nghệ tiên tiến của thế giới vào hoạt động sản xuất của gia đình. Khoảng cách từ nhà tới ruộng lúa trung bình $4 \mathrm{~km}$ nhưng vẫn có hộ cách xa ruộng xa nhất là $13 \mathrm{~km}$, điều này cũng gây trở ngại trong việc quản lý và chăm sóc ruộng lúa của nông hộ có thể sẽ làm ảnh hưởng đến hiệu quả sản xuất của hộ.

\section{Bảng 3}

Diện tích và năng suất đất trong canh tác lúa của nông hộ

\begin{tabular}{lccc}
\hline \multicolumn{1}{c}{ Tiêu chí } & Đơn vị tính & Trung bình & Độ lệch \\
\hline Quy mô trồng lúa & Ha & 2,47 & 2,51 \\
Năng suất đất vụ Đông xuân & Triệu đồng/ha & 14,96 & 7,82 \\
Năng suất đất vụ Hè thu & Triệu đồng/ha & 11,63 & 7,39 \\
Năng suất đất vụ Thu đông & Triệu đồng/ha & 13,97 & 8,10 \\
\hline
\end{tabular}

Nguồn: Kết quả được tổng hợp từ số liệu tự khảo sát năm 2017

Quy mô đất trồng lúa của nông hộ trung bình là 2,47 ha với biến động khá lớn (độ lệch chuẩn 2,51 ha). Đây chính là hạn chế rất lớn trong việc áp dụng cơ giới hóa vào sản xuất đã làm gia tăng chi phí và giảm hiệu quả sản xuất cho nông hộ.

Năng suất đất vụ lúa đông xuân là cao nhất trong 3 vụ với mức trung bình là 14,96 triệu đồng/ha với độ lệch là 7,82 triệu/ha. Đây là vụ sản xuất có hiệu quả cao nhất so với các vụ lúa khác trong năm do điều kiện thời tiết thuận lợi cho cây lúa phát triển và đây cũng là mùa vụ được nông hộ ưu tiên đầu tư sản xuất để mang lại thu nhập cho gia đình. Mùa vụ mang lại hiệu quả thấp nhất vẫn là vụ hè thu chỉ đạt 11,63 triệu đồng/ha.

\section{Bảng 4}

Những rủi ro thường gặp của nông hộ ĐBSCL

\begin{tabular}{lcc}
\hline \multicolumn{1}{c}{ Tiêu chí } & Số quan sát & Tỷ trọng (\%) \\
\hline Bị ảnh hưởng bởi thiên tai (lũ lụt, hạn hán, . . .) & 19 & 5,64 \\
Mất mùa, dịch bệnh & 124 & 36,80 \\
\hline
\end{tabular}




\begin{tabular}{lcc}
\hline \multicolumn{1}{c}{ Tiêu chí } & Số quan sát & Tỷ trọng (\%) \\
\hline Giá sản phẩm thấp và không ổn định & 171 & 50,74 \\
Giá vật tư nông nghiệp tăng bất ngờ & 23 & 6,82 \\
Tổng cộng & 337 & 100,00 \\
\hline
\end{tabular}

Nguồn: Kết quả được tổng hợp từ số liệu tự khảo sát năm 2017

Nông hộ thường gặp khá nhiều rủi ro trong sản xuất, trong đó rủi ro lớn nhất là giá sản phẩm thấp và không ổn định chiếm $50,74 \%$. Nguyên nhân chủ yếu là do trên $80 \%$ nông hộ thường bán sản phẩm ngay sau khi thu hoạch cho thương lái và chịu sự chi phối của thương lái từ giá cả, số lượng cho đến chất lượng sản phẩm (độ ẩm, kích thước hạt, ...), điều này đã mang lại nhiều thiệt thòi cho nông hộ bởi thương lái vừa là người mua, vừa là người cung cấp thông tin giá cả nên toàn quyền định đoạt giá, trong khi nông hộ là người sản xuất và cung ứng sản phẩm chỉ biết chấp nhận giá do thương lái ấn định. Mặt khác, số ít nông hộ bán sản phẩm thông qua hợp tác xã, các chợ gần nhà. Chính những điều này đã ảnh hưởng rất lớn đến nguồn thu nhập và sinh kế của nông hộ bởi lúa là sản phẩm chủ lực của hộ. Rủi ro tiếp theo là mất mùa và dịch bệnh chiếm $36,80 \%$ do tác động của biến đổi khí hậu gây khó khăn cho nông hộ trong việc phòng ngừa và tránh rủi ro.

\subsection{Mối quan hệ giữa quy mô và năng suất đất}

Bài viết sử dụng phương pháp hồi qui tuyến tính để ước lượng mô hình (3) nhằm xác định mối quan hệ giữa quy mô và năng suất đất của nông hộ trồng lúa ở ĐBSCL. Sau khi thực hiện hết tất cả các kiểm định có liên quan đến mô hình hồi qui tuyến tính thì nhận thấy mô hình chỉ vi phạm giả thiết về phương sai sai số thay đổi. Kết quả ước lượng sau khi khắc phục hiện tượng phương sai sai số thay đổi được trình bày chi tiết ở Bảng 5 .

Kết quả ước lượng cho thấy, các mô hình đều có ý nghĩa rất cao (1\%), riêng mô hình (1) chỉ có ý nghĩa (5\%) ngoại trừ mô hình (7) không có ý nghĩa và đã chỉ ra được mối quan hệ phi tuyến có dạng chữ $\cap$ giữa quy mô và năng suất đất. Tuy nhiên, $\mathrm{R}^{2}$ trong các mô hình khá thấp $(3 \%-18 \%)$ cho thấy các yếu tố này chỉ kiểm soát được từ $3 \%-18 \%$ sự biến động của năng suất đất, trong khi những yếu tố không quan sát được lại quyết định phần lớn năng suất đất.

\section{Bảng 5}

Kết quả ước lượng mối quan hệ giữa quy mô và năng suất đất

Biến phụ thuộc: NSDAT - Năng suất đất của hộ (triệu đồng/ha)

\begin{tabular}{cccccccccc}
\hline \multirow{2}{*}{ Biến số } & \multicolumn{3}{c}{ Vụ Đông Xuân } & \multicolumn{3}{c}{ Vụ Hè Thu } & \multicolumn{3}{c}{ Vụ Thu đông } \\
\cline { 2 - 10 } & $\mathbf{( 1 )}$ & $\mathbf{( 2 )}$ & $\mathbf{( 3 )}$ & $\mathbf{( 4 )}$ & $\mathbf{( 5 )}$ & $\mathbf{( 6 )}$ & $\mathbf{( 7 )}$ & $\mathbf{( 8 )}$ & (9) \\
\hline QUYMO & 0,147 & $0,923^{* *}$ & $1,220^{* * *}$ & $1,187^{* * *}$ & $1,182^{* * *}$ & $1,083^{* *}$ & $0,825^{* *}$ & $1,254^{* * *}$ & $1,210^{* *}$ \\
QUYMOSQ & $-0,028$ & $-0,067^{* *}$ & $-0,085^{* * *}$ & $-0,078^{* * *}$ & $-0,082^{* * *}$ & $-0,078^{* *}$ & $-0,064^{* *}$ & $-0,088^{* * *}$ & $-0,087^{* *}$ \\
QUYMOHO & & 0,455 & 0,517 & & 0,528 & $0,643^{* *}$ & & 0,416 & 0,544 \\
\hline
\end{tabular}




\begin{tabular}{|c|c|c|c|c|c|c|c|c|c|}
\hline \multirow{2}{*}{ Biến số } & \multicolumn{3}{|c|}{ Vụ Đông Xuân } & \multicolumn{3}{|c|}{ Vụ Hè Thu } & \multicolumn{3}{|c|}{ Vụ Thu đông } \\
\hline & (1) & (2) & (3) & (4) & (5) & (6) & (7) & (8) & (9) \\
\hline TGDINHCU & & $-0,025$ & 0,001 & & $-0,050^{*}$ & $-0,017$ & & $-0,050^{*}$ & $-0,013$ \\
\hline TNKHAC & & 0,017 & 0,011 & & 0,017 & 0,017 & & 0,025 & 0,023 \\
\hline TINDUNG & & 0,021 & 0,022 & & 0,023 & 0,023 & & 0,026 & 0,025 \\
\hline TRAVINH & & $6,766^{* * *}$ & $6,675 * * *$ & & $2,390^{* * *}$ & $1,969^{* *}$ & & $5,138 * * *$ & $4,758^{* * *}$ \\
\hline RUIRO & & 1,102 & 0,752 & & 0,563 & 0,237 & & 0,633 & 0,255 \\
\hline KCRUONG & & & $-0,311^{*}$ & & & $-0,481^{* * *}$ & & & $-0,581 * * *$ \\
\hline THAMNIEN & & & $-0,059$ & & & $-0,057$ & & & $-0,069$ \\
\hline PHUSA & & & $-0,966$ & & & $-2,576$ & & & $-1,856$ \\
\hline TAPHUAN & & & $4,158^{* * *}$ & & & 0,847 & & & 1,872 \\
\hline Hằng số & $14,939^{* * *}$ & $8,939^{* * *}$ & $7,895^{*}$ & $9,671^{* * *}$ & $8,183^{* * *}$ & $12,465^{* * *}$ & $12,720^{* * *}$ & $9,387^{* * *}$ & $12,571^{* * *}$ \\
\hline Số quan sát & 337 & 337 & 337 & 337 & 337 & 337 & 337 & 337 & 337 \\
\hline $\mathrm{R}^{2}$ & 0,0053 & 0,1472 & 0,1855 & 0,0316 & 0,0747 & 0,1041 & 0,0125 & 0,1007 & 0,1371 \\
\hline Prob $>F$ & 0,0147 & 0,0000 & 0,0000 & 0,0041 & 0,0001 & 0,0000 & 0,1023 & 0,0000 & 0,0000 \\
\hline
\end{tabular}

Ghi chú: (*) có mức ý nghĩa 10\%, (**) có mức ý nghĩa 5\%, (***) có mức ý nghĩa $1 \%$

Nguồn: Kết quả được ước lượng từ số liệu tự khảo sát năm 2017

Khi phân tích mô hình giản đơn chỉ có 2 yếu tố là quy mô và năng suất đất, cả ba vụ đều cho thấy mối quan hệ tích cực (quan hệ thuận) giữa quy mô và năng suất đất, ngoại trừ vụ đông xuân (cột 1) là không có ý nghĩa thống kê do đây là vụ có sự biến động lớn giữa các quan sát so với 2 vụ kia. Tuy nhiên, khi bổ sung thêm những ràng buộc khác về đặc điểm của hộ ảnh hưởng đến năng suất đất thì tất cả các vụ trồng lúa đều có mối quan hệ phi tuyến có dạng chữ $\cap$ giữa quy mô và năng suất đất với mức ý nghĩa rất cao $1 \%$. Điều này hoàn toàn đúng với giả thiết (Barrett et al., 2010; Byiringiro \& Reardon, 1996; Dorward, 1999) và nghiên cứu thực nghiệm của họ ở châu Phi. Đồng thời kết quả ước lượng cũng cho thấy, tất cả các biến có ý nghĩa đều ảnh hưởng đến năng suất đất trong cả 3 vụ sản xuất với kết quả chênh lệch tương đối. Điều này chứng tỏ nông hộ có sự đầu tư tương đối đồng đều ở các vụ canh tác lúa trong năm nhưng do khác biệt trong giá các yếu tố đầu vào cũng như sự thay đổi của điều kiện tự nhiên. Một sự thay đổi trong TGDINHCU cũng đều có tác động tiêu cực đến năng suất đất canh tác lúa như nhau trong cả vụ hè thu và thu đông nhưng không tác động đến vụ đông xuân, nhất là khi nông hộ sinh sống ở Trà Vinh sẽ đạt năng suất đất cao hơn những hộ sinh sống ở Hậu Giang hay Kiên Giang.

Sau khi bổ sung tất cả các yếu tố ảnh hưởng đến năng suất đất để ước lượng mô hình đầy đủ thì nhận thấy các biến quan sát quan trọng vẫn tương đối ổn định, nghĩa là ngoài biến QUYMO thì biến TRAVINH ảnh hưởng tích cực đến năng suất đất ở cả ba vụ canh tác lúa nhưng với hệ số ước lượng có sự chênh lệch nhau giữa các vụ. Riêng biến QUYMOHO chỉ ảnh hưởng tích cực đến vụ hè thu. 
Biến dummy TRAVINH có hệ số dương ở mức ý nghĩa $1 \%$, cho thấy có sự khác biệt khá lớn về năng suất đất ở Trà Vinh so với Hậu Giang và Kiên Giang.

Biến QUYMOHO có hệ số dương ở mức ý nghĩa 5\% chỉ trong vụ hè thu nhưng không có ý nghĩa ở hai vụ còn lại, ngụ ý nếu số thành viên trong độ tuổi lao động của hộ càng nhiều thì sẽ giúp nông hộ tiết kiệm được nhiều chi phí thuê mướn lao động do vụ này đòi hỏi nhiều lao động để phục vụ cho bón phân, xịt sâu; đồng thời có thể dễ dàng quản lý, kiểm soát động cơ làm việc cũng như trách nhiệm trong công việc hơn so với thuê lao động địa phương. Từ đó, làm gia tăng năng suất đất.

Riêng hệ số ước lượng của biến QUYMO có trị số dương và biến QUYMOSQ có trị số âm với cùng mức ý nghĩa $1 \%$ vụ đông xuân nhưng hai vụ hè thu và thu đông có mức ý nghĩa thấp hơn là $5 \%$. Từ kết quả này, lấy đạo hàm riêng bậc nhất của NSDAT theo QUYMO có thể tìm được ngưỡng quy mô tối đa ứng với từng vụ sản xuất, hàm ý đây là ngưỡng quy mô tối ưu giúp nông hộ đạt được năng suất đất lớn nhất bởi nếu sản xuất vượt ngưỡng quy mô tối ưu này thì sản xuất sẽ kém hiệu quả do (i) nông hộ phải thuê mướn nhiều lao động hơn và khó kiểm soát động cơ làm việc của họ, (ii) Nhu cầu về các yếu tố đầu vào tăng cao nhưng nguồn vốn hạn chế cùng với thị trường yếu tố đầu vào kém phát triển nên khó đảm bảo chất lượng các yếu tố đầu vào, và (iii) Năng lực quản lý của nông hộ thấp do trình độ học vấn thấp. Do đó, để mang lại hiệu quả cao nhất trong sản xuất lúa nông hộ nên đầu tư ở quy mô hợp lý cho từng vụ mùa, dao động trong khoảng quy mô từ 6,94 ha - 7,18 ha, thể hiện chi tiết ở Bảng 6 .

\section{Bảng 6}

Ngưỡng quy mô tối ưu trong sản xuất lúa của nông hộ ĐBSCL

\begin{tabular}{ccc}
\hline Mùa vụ & Đơn vị tính & Quy mô tối đa \\
\hline Đông xuân & Ha & 7,18 \\
Hè thu & Ha & 6,94 \\
Thu đông & Ha & 6,95 \\
\hline
\end{tabular}

Nguồn: Kết quả được tổng hợp từ số liệu tự khảo sát năm 2017

Bên cạnh đó, trong số các yếu tố thuộc khả năng quản lý và chất lượng đất của chủ hộ thì biến KCRUONG có hệ số âm ứng với các mức ý nghĩa khác nhau ở ba vụ, cụ thể có mức ý nghĩa $1 \%$ ở vụ hè thu và thu đông, nhưng vụ đông xuân chỉ có ý nghĩa ở mức $10 \%$, ngụ ý rằng khoảng cách từ nhà nông hộ đến ruộng lúa càng gần thì năng suất đất càng cao do dễ dàng và thuận tiện trong việc quản lý cũng như chăm sóc ruộng lúa. Biến TAPHUAN cũng tương tự biến QUYMOHO nhưng lại có mức ý nghĩa cao 1\% đối với vụ đông xuân, hàm ý việc nông hộ tham gia tập huấn đã làm gia tăng đáng kể năng suất đất vụ đông xuân $(4,16$ triệu đồng/ha) nhờ được hỗ trợ các kiến thức chủ yếu về chọn giống, sử dụng phân bón, nông dược; về kỹ thuật trồng lúa.

\section{Kết luận}

Kết quả ước lượng cho thấy mối quan hệ phi tuyến có dạng chữ $\cap$ giữa quy mô và năng suất đất trong canh tác lúa của nông hộ ĐBSCL, bên cạnh quy mô thì còn nhiều yếu tố khác 
cũng ảnh hưởng tích cực đến năng suất đất với mức ý nghĩa cao đó là: việc tham gia các lớp tập huấn của nông hộ, số thành viên trong độ tuổi lao động của hộ, địa bàn nơi cư trú của nông hộ và yếu tố ảnh hưởng tiêu cực đến năng suất đất là khoảng cách từ nhà nông hộ đến ruộng lúa. Đồng thời, kết quả ước lượng cũng tìm được ngưỡng quy mô tối ưu tương đối giống nhau cho cả ba vụ canh tác lúa là 7 ha (có nghĩa là nếu nông hộ đang canh tác lúa có quy mô thấp hơn hoặc cao hơn ngưỡng tối ưu này thì nên mở rộng hoặc thu hẹp quy mô để đạt năng suất đất tối đa) cho nông hộ trồng lúa ở ĐBSCL nhằm giúp họ có kế hoạch đầu tư và sử dụng hiệu quả quy mô để đạt hiệu quả cao nhất góp phần gia tăng thu nhập và cải thiện sinh kế. Từ kết quả nghiên cứu và thực tế ở 3 tỉnh Kiên Giang, Trà Vinh và Hậu Giang thuộc ĐBSCL, nghiên cứu có một số khuyến nghị nhằm giúp nông hộ sử dụng và đầu tư quy mô hợp lý góp phần nâng cao năng suất đất như sau:

Nhà nước nên điều chỉnh Điều 129 của Luật đất đai 2013 thông qua thu hẹp hạn mức giao đất trồng cây hàng năm cho mỗi hộ gia đình, cá nhân trực tiếp sản xuất nông nghiệp ở mức 7 ha/hộ cho mỗi loại đất đối với tỉnh, thành phố trực thuộc trung ương thuộc khu vực Đông Nam Bộ và khu vực Đồng bằng sông Cửu Long nhằm giúp nông hộ an tâm đầu tư sản xuất trên chính mảnh ruộng của mình, sử dụng và đầu tư đúng với ngưỡng quy mô tối đa và áp dụng cơ giới hóa vào sản xuất.

Đa dạng hóa hệ thống trường lớp ở nông thôn và có chính sách hỗ trợ, khuyến khích người dân (nhất là những chủ hộ, những người trực tiếp sản xuất lúa) đến học để nâng cao trình độ giúp tiếp cận nhanh những công nghệ tiên tiến trên thế giới và vận dụng hiệu quả vào hoạt động sản xuất của hộ.

Xây dựng cơ chế và chính sách ưu tiên cho cây lúa để giảm bớt lượng cung lúa gạo bằng việc luân phiên canh tác và cho đất nghỉ ngơi vụ thu đông mỗi tỉnh một năm nhằm (i) Gia tăng độ phì nhiêu cho đất, (ii) Cải tạo và bồi dưỡng đất, (iii) Tạo sự khan hiếm và tăng giá sản phẩm trên trường quốc tế.

Nông hộ đang canh tác trên quy mô nhỏ hơn ngưỡng tối ưu nên mua hoặc thuê thêm đất để canh tác, nên hợp tác với những hộ canh tác lúa lân cận có quy mô nhỏ để mở rộng quy mô sản xuất với hình thức tổ/nhóm canh tác lúa, hoặc tính toán đến việc tham gia mô hình cánh đồng mẫu lớn, ... nhằm đảm bảo quy mô tối ưu, nâng cao chất lượng cũng như tăng cường khả năng tiêu thụ sản phẩm, qua đó giúp đạt năng suất đất tối đa.

\section{Tài liệu tham khảo}

Ali, D. A., \& Deininger, K. (2015). Is there a farm size-productivity relationship in African agriculture? Evidence from Rwanda. Land Economics, 91(2), 317-343.

Assuncao, J. J., \& Ghatak, M. (2003). Can unobserved heterogeneity in farmer ability explain the inverse relationship between farm size and productivity. Economics Letters, 80(2), 189-194.

Barrett, C. B., Bellemare, M. F., \& Hou, J. Y. (2010). Reconsidering conventional explanations of the inverse productivity-size relationship. World Development, 38(1), 88-97. 
Bhalla, S. S., \& Roy, P. (1988). Mis-specification in farm productivity analysis: The role of land quality. Oxford Economic Papers, 40(1), 55-73.

Byiringiro, F., \& Reardon, T. (1996). Farm productivity in Rwanda: Effects of farm size, erosion, and soil conservation investments. Agricultural Economics, 15(2), 127-136.

Carter, M. R. (1984). Identification of the inverse relationship between farm size and productivity: An empirical analysis of peasant agricultural production. Oxford Economic Papers, 36(1), 131-145.

Dorward, A. (1999). Farm size and productivity in Malawian smallholder agriculture. The Journal of Development Studies, 35(5), 141-161.

Gaurav, S., \& Mishra, S. (2015). Farm size and returns to cultivation in India: Revisiting an old debate. Oxford Development Studies, 43(2), 165-193.

Heltberg, R. (1998). Rural market imperfections and the farm size-productivity relationship: Evidence from Pakistan. World Development, 26(10), 1807-1826.

Lamb, R. L. (2003). Inverse productivity: Land quality, labor markets, and measurement error. Journal of Development Economics, 71(1), 71-95.

Li, G., Feng, Z., You, L., \& Fan, L. (2013). Re-examining the inverse relationship between farm size and efficiency: The empirical evidence in China. China Agricultural Economic Review, 5(4), 473-488.

Mahmood, M., \& Nadeem-ul-haque. (1981). Farm size and productivity revisited. The Pakistan Development Review, 20(2), 151-190.

Nkonde, C., Jayne, T. S., Richardson, R., \& Place, F. (2015). Testing the farm size productivity relationship over a wide range of farm sizes: Should the relationship be a decisive factor in guiding agricultural development and land policies in Zambia. Paper presented at the World Bank Land and Poverty Conference, Washington, DC.

Pham, H. V., MacAulay, T. G., \& Marsh, S. P. (2007). The economics of land fragmentation in the North of Vietnam. Australian Journal of Agricultural and Resource Economics, 51(2), 195-211.

Pham, T. L., Huynh, X. T. D., \& Tran, D. T. T. (2011). So sánh hiệu quả kinh tế của vụ lúa hè thu và thu đông ở Đồng bằng sông Cửu Long [Comparing the economic efficiency of summer-autumn and autumn-winter rice crops in the Mekong Delta]. Tap chí Khoa hoc Đại học Cần Tho, 18(a), 267-276.

Tan, S., Heerink, N., Kuyvenhoven, A., \& Qu, F. (2010). Impact of land fragmentation on rice producers' technical efficiency in South-East China. NJAS-Wageningen Journal of Life Sciences, 57(2), 117-123.

Tổng cục Thống kê. (2016). Niên giám thống kê [Statistical yearbook of vietnam 2016]. Retrieved from October 11, 2018, from https://www.gso.gov.vn/en/data-andstatistics/2019/10/statistical-yearbook-of-vietnam-2016/ 
Wu, Z., Liu, M., \& Davis, J. (2005). Land consolidation and productivity in Chinese household crop production. China Economic Review, 16(1), 28-49.

Xu, X., \& Jeffrey, S. R. (1998). Efficiency and technical progress in traditional and modern agriculture: Evidence from rice production in China. Agricultural Economics, 18(2), 157165.

Yamano, T., \& Kijima, Y. (2010). The associations of soil fertility and market access with household income: Evidence from rural Uganda. Food Policy, 35(1), 51-59. 